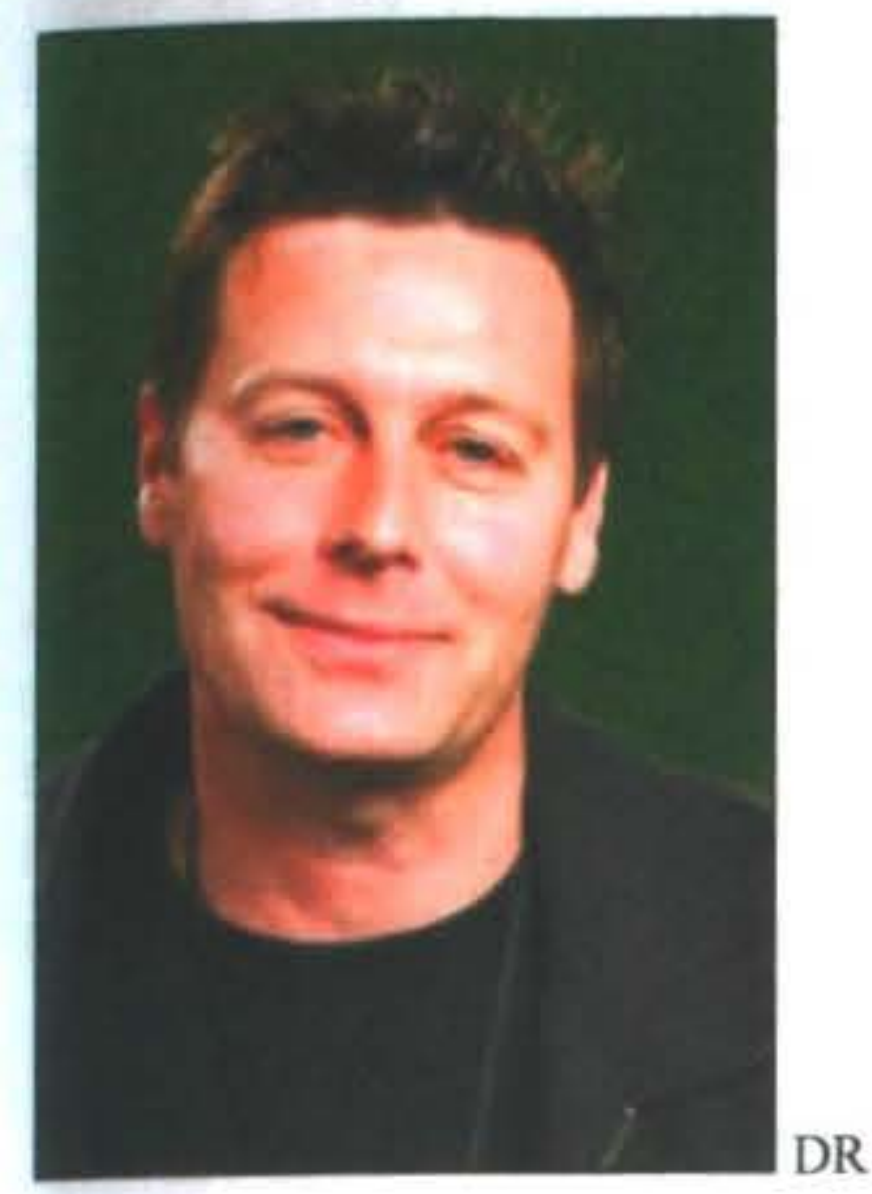

\title{
COHORTS EXPERIENCES OF YOUTH LABOUR MARKET TRANSITIONS IN NEW ZEALAND
}

\author{
David Rea and Paul Callister \\ Institute of Policy Studies, \\ Victoria University of Wellington
}

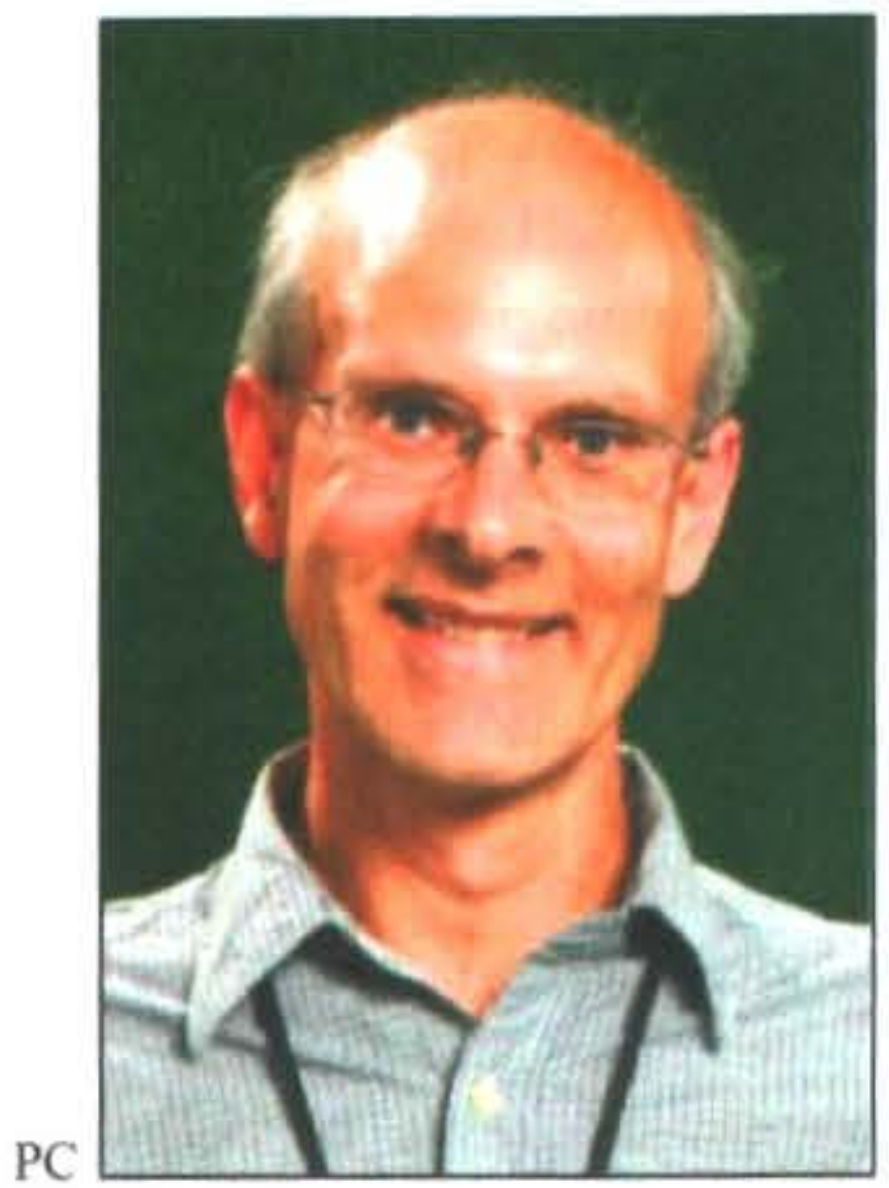

Abstract

This paper investigates the changing nature of young peoples' transition into the labour market over the last 30 years. The paper uses census data from 1976 to 2006 to compare the experiences of cohorts of young people born in New Zealand. A range of outcomes are analysed including living with parents, participation in education, employment, partnering, having children and migration. We find that transitions into the labour market have changed considerably over the last 30 years. We also find that the cohorts of young people born in the late 1960s and early 1970 s experienced somewhat different outcomes compared to both the preceding as well as later cohorts. We attribute this to the fact that these cohorts entered the labour market in the late 1980s and early 1990s at a time of high overall unemployment. Our findings have important policy implications, particularly given the current recession and rising rates of youth unemployment.

\section{Introduction}

There is considerable popular discussion of the differences between young people today and previous generations. Frequently the comment is made that young people today are not interested in careers, that they are not reliable employees, and are less responsible with money than previous generations. Usually the rejoinder to this assertion is to point out that such sentiments have often been expressed by older generations. For example, the 1954 Report of the Special Committee on Moral Delinquency in Children and Adolescents argued that:

\footnotetext{
'The starting wage for adolescents is often somewhat high, and thrift is not practised by them. A few years hence, these adolescents may be in the ranks of those who complain of their inability to obtain homes. This has prompted people to urge that a compulsory savings scheme should be instituted to guard young people from the evils of misspent leisure and to develop in them that sense of reliability which is so often lacking. (Mazengarb et. al., 1954 p40)
}

In this paper we look at what the empirical evidence suggests about transitions of young people today compared with previous generations. Using mainly Census data we look at how different birth cohorts have participated in education, left home, entered the labour market, formed partnerships, had children, and undertaken other transitions such as leaving the country. Our basic research question is: how has the nature of young peoples transition into the labour market changed in the last 30 years?
This paper draws on our wider study of the transition to adulthood amongst cohorts of young people in New Zealand over the last 30 years (Rea and Callister, 2009).

The rest of this paper is structured in the following manner. We first briefly explain our conceptual framework of youth transitions. Second, we set out our empirica! methodology. Third, we report our findings. The fourth section presents some analysis of our findings. The fifth section discusses the policy implications of our findings, and the last section concludes.

\section{The transition to adulthood}

A useful perspective from which to analyse 'adolescence' is to see youth as a stage of life that involves both the preparation for, and the transitions to, adult roles and responsibilities. This perspective is implicit in the analysis of young people embedded in a wide range of disciplines including anthropology, sociology and economics (Setterson et al., 2005; Schlegal and Barry, 1991; Ryan, 2001). Overall this perspective views young people as moving from dependence within families to independence within wider society.

Key aspects of the transition to adulthood include leaving school, leaving home, getting a job, gaining a drivers license, living with a partner, and sometimes becoming a parent. 
The notion of the transition to adult roles and responsibilities focuses attention on both the process of preparation - for example learning the skills to drive a car - as well as the transition to a new role or activity for example owning and driving a car independently.

The perspective focuses attention on many different aspects of the transition to adulthood. These include changing living arrangements, changing economic activities, and changing rights and responsibilities as citizens. Transitions can occur in different ways, at different times, and do not necessarily involve a linear sequential process.

Youth is a time of both vulnerability and resilience. Some of this vulnerability arises because of the mistakes and accidents that occur as part of learning new skills and undertaking new activities. Many young people are also resilient, and tend to 'bounce-back' from adversity.

Experiences and choices during adolescence often have long-term consequences. Choices about subject of study at school, career jobs, partners, and of course fertility all have long term consequences to varying degrees.

Youth transitions are socially constructed rather than biologically determined. While physiological changes (including brain development) are occurring for young people, it is clear that the nature of the transition to adulthood occurs in different ways across societies, and within the same society across time.

While we find it useful to characterise 'youth' as a process of learning and transitions - it is important to recognise that process of learning and the adoption of new roles and responsibilities occurs amongst people of all ages. What is distinctive is that youth is a particularly concentrated time of learning and transition into new roles and responsibilities.

Labour market transitions - from education into paid work - are an important subset of the process of a wider process of becoming an adult. In the labour market context, preparation for adult roles involves learning economically useful skills, both within formal education, as well as the family and wider community. The transition into employment involves finding a job, informal and formal learning on the job, and often moving to a different job that might be more suited.

There is a significant amount of heterogeneity in the nature of youth jobs - from short-term temporary employment, to longer term careers jobs. As a result of many of these factors, youth labour markets tend to be characterised by lower wages, higher levels of training, higher turnover, and more frequent spells of unemployment (Ryan, 2001).

The transition to adulthood perspective does not imply that young people are of less value than adults. Nor should it be seen as a comprehensive view of young people. There are many more aspects to young people than preparation and transitions to adult roles and responsibilities.

\section{Methodology}

The paper uses a pseudo cohort methodology drawing on data from the 1976 to 2006 census (Deaton, 1985). We use the five yearly Census to construct repeated observations of cohorts who were born in New Zealand within the same five year period. We observe outcomes for the following eight birth cohorts:

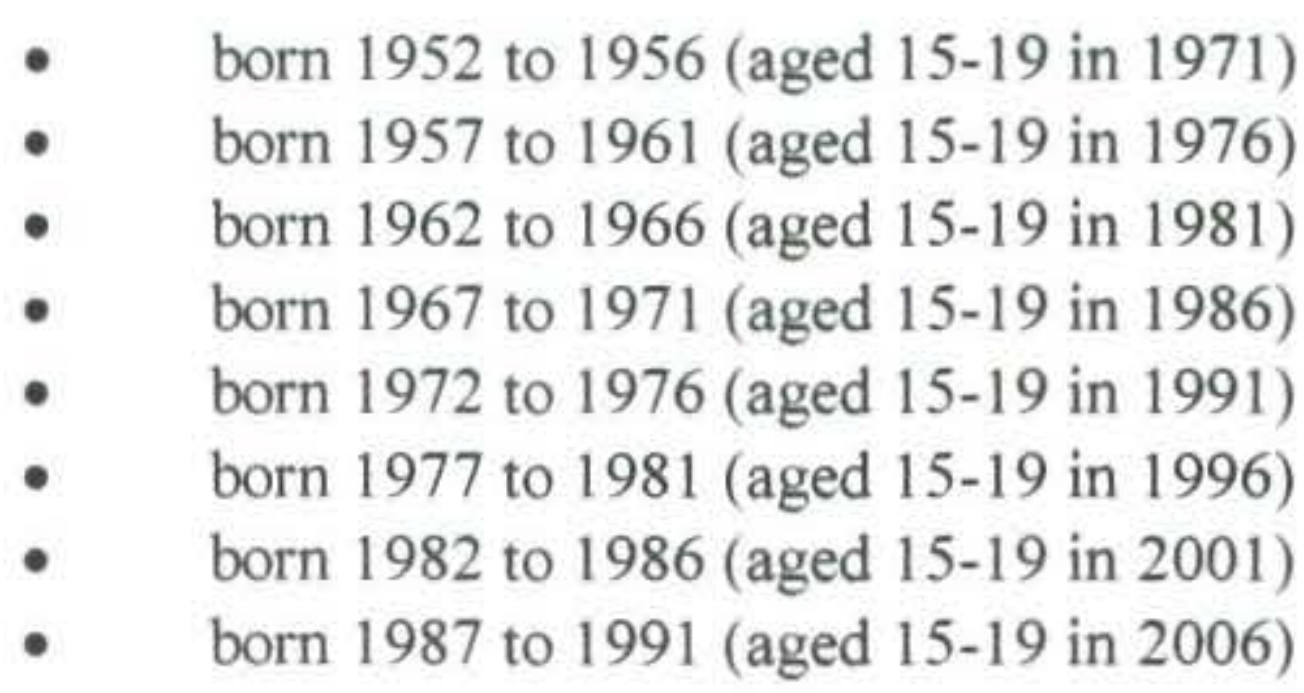

For the most part we simply compare the outcomes for each cohort. We look at outcomes when the cohorts were 15-19, 20-24 and 25-29 years of age. The outcomes we analyse are:

- $\quad$ living with parents

- $\quad$ living with a partner and marriage

- $\quad$ living with dependent children (as a couple and as a sole parent)

- participation in education

- participation in employment (full-time and parttime)

- unemployment

- $\quad$ receipt of an income-tested benefit in the last 12 months

- real mean personal income

- religious affiliation

- $\quad$ proportion living in rural and urban areas

- migration from New Zealand

- mortality.

All the outcomes are measured using census data, with the exception of participation in education and mortality where we use administrative data.

Figure 1 provides an example of how we compare cohort outcomes. The outcome in this instance is the proportion of the birth cohort recorded as living with their parents at selected ages. Figure 1 compares the experience of only two cohorts, and shows the census year in which the relevant information was collected for each cohort. Figure 1 shows the relationship between age and living with parents, and also allows comparison between cohorts. 
Figure 1: Proportion living with parents at ages 15-19, 20-24 and 25-29 years, selected cohorts

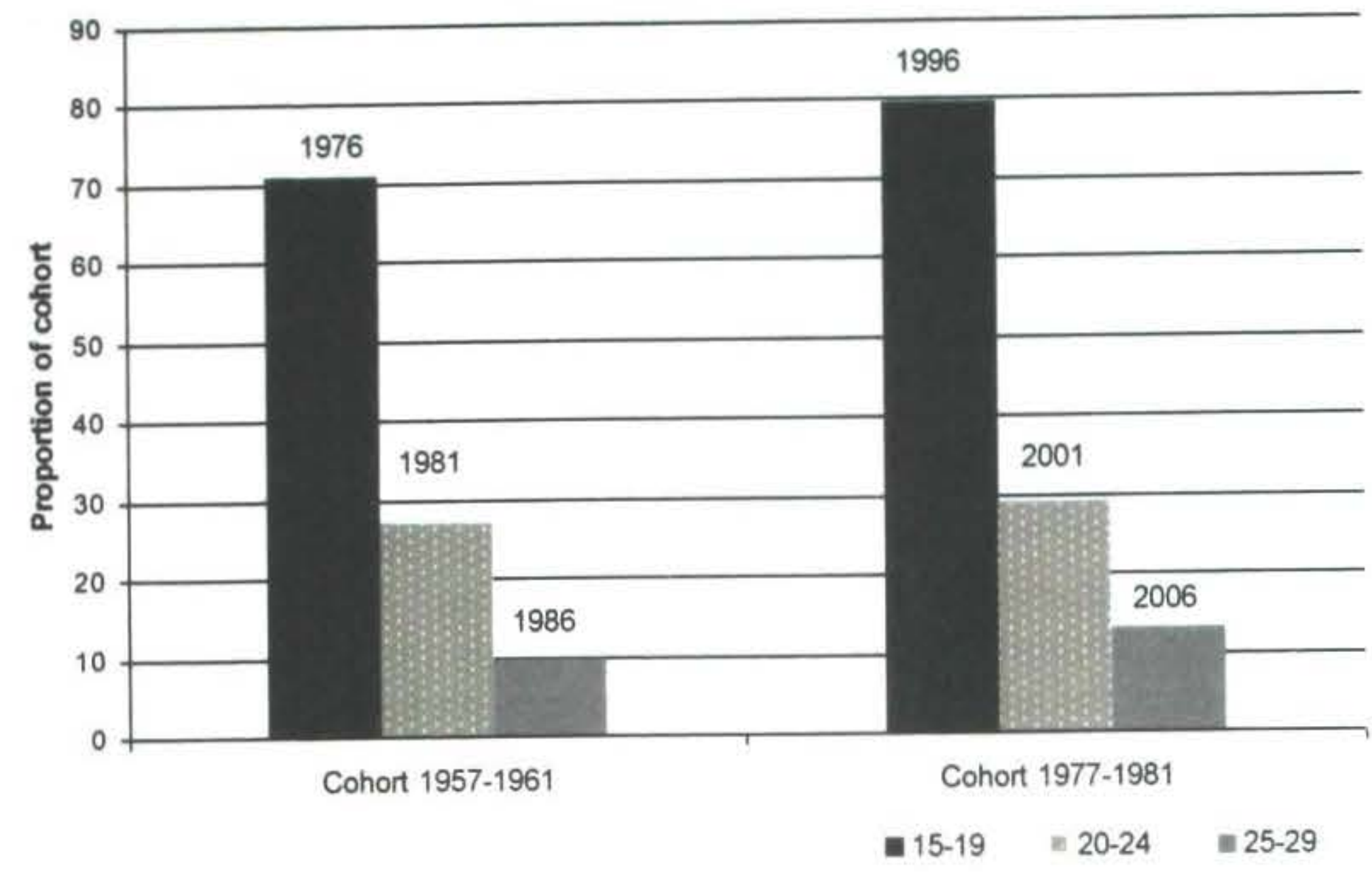

Source: Rea and Callister (2009)

We are able to compare the experiences of young women and men across all the outcomes we analyse. To a limited extent we are also able to analyse outcomes by ethnicity. Unfortunately, the changes in how ethnicity has been recorded means there is only consistent Census data available from 1991. Our analysis of ethnic differences is also hampered by the likely possibility of people shifting ethnic affiliation overtime (Statistics New Zealand, 2005). The net result is that we have only limited insights about the potentially very interesting changes that have occurred for cohorts of young people of different ethnicities.

Our methodology has a number of limitations, but three of the most important are as follows.

First, the composition of the New Zealand born cohorts changes through time because of survey non response, migration from New Zealand, and death. This means that differences in composition, rather than behaviour, may at time be responsible for observed differences in outcomes of the cohorts. Despite this, we are of the view that differences in compositional change account for very little of the observed cohort differences.

Second, we are dealing with aggregate statistics that mask the considerable heterogeneity within the youth population. There are many subgroups and significant variation that is hidden by the averaging process of our statistics.

Third, we are relying mainly on census data, which provides only a very limited window into the actual lives of young people. Many important aspects of the lives of young people are not recorded by a short questionnaire administered every five years.

Fuller details of the nature of the variables used, our methodology, and its various limitations are provided in Rea and Callister (2009).

\section{Findings}

In what follows we describe the results for each of the different outcome analysed.

\section{Living with parents}

As young people get older they become less likely to live with their parents. At any given age, a smaller proportion of young women live with their parents compared to young men. Young people identifying as Maori and European are also less likely to live with their parents

The long term trend has been of young people living with their parents' for longer. Young people born in 1980 s were more likely to live with their parents than the cohort born in the 1950s. However within this long-term trend, the cohorts born in the late 1960s and early 1970 s had an unusually high prevalence of living with their parents.

\section{Partnering and marriage}

As young people get older they are progressively more likely to be living with a partner. Young women are more likely to be partnered that young men, and Maori and European are more likely than other ethnic groups to be living with a partner.

More recent cohorts are less likely to be living with a partner than earlier cohorts. There have also been dramatic changes in the nature of partnership. For early cohorts, the majority of young people who were partnered were married. For later cohorts, less than half of those who are living with a partner were married.

\section{Living with dependent children}

As young people get older they become more likely to live with dependent children of their own. Young 
women are more likely than young men to be living with dependent children. Young people identifying as Maori and Pacific are also more likely to be living with dependent children.

Like partnership, there has also been a significant change in the extent to which young people have, and are recorded as living with, dependent children. More recent cohorts of young women are less likely to be living with children. The decline in living with dependent children has been even more pronounced amongst later cohorts of young men.

If we look at the partnership arrangements of young people living with dependent children, there are important changes occurring. Over the last 30 years, the prevalence of living with dependent children as a sole parent has increased, and then decreased amongst both young women, and to a more limited extent, amongst young men. These changes reflect both changes in fertility (which has declined), and also partnership arrangements of young parents (which have fluctuated). The cohort born in the years 1972-1976 had the highest prevalence of sole parenthood amongst all the youth cohorts.

\section{Participation in education}

As young people get older they become less likely to participate in education. Amongst recent cohorts, young women are more likely than young men to be in education. Asian and European young people have the highest rates of participation in education.

Over the last 30 years there has been a sustained rise in the extent to which young people participate in education. As an example of the increase - amongst the cohort born in the early 1950 's, only around $20 \%$ were participating in education at 20 years of age. Amongst the cohort born in the early $1980 \mathrm{~s}$, around $50 \%$ of 20 year olds were recorded as participating in education. ${ }^{1}$

The growth in educational participation has occurred disproportionately in the tertiary sector. An increasing proportion of young people are attending tertiary institutions, and gaining post school qualifications.

Over the last 30 years the growth in educational participation amongst young women has been more rapid than for men. Amongst earlier cohorts young men were more likely to participate in education than young women. Amongst more recent cohorts the reverse is true.

\section{Participation in employment}

In general, as young people get older they are more likely to be in paid work.

At any age, young men are more likely to be employed than young women. Young people identifying as European and the 'Other' category are more likely to be employed than young people identifying with other ethnic groups.

Figure 2 shows the changes across cohorts of young men in relation to full-time employment. As can be seen, the proportion of young men in full-time employment has declined. This reflects a delay in entry to full-time employment because participation in education has increased.

Figure 2: Proportion of young men in full time employment at ages 15-19, 20-24 and 25-29, selected cohorts

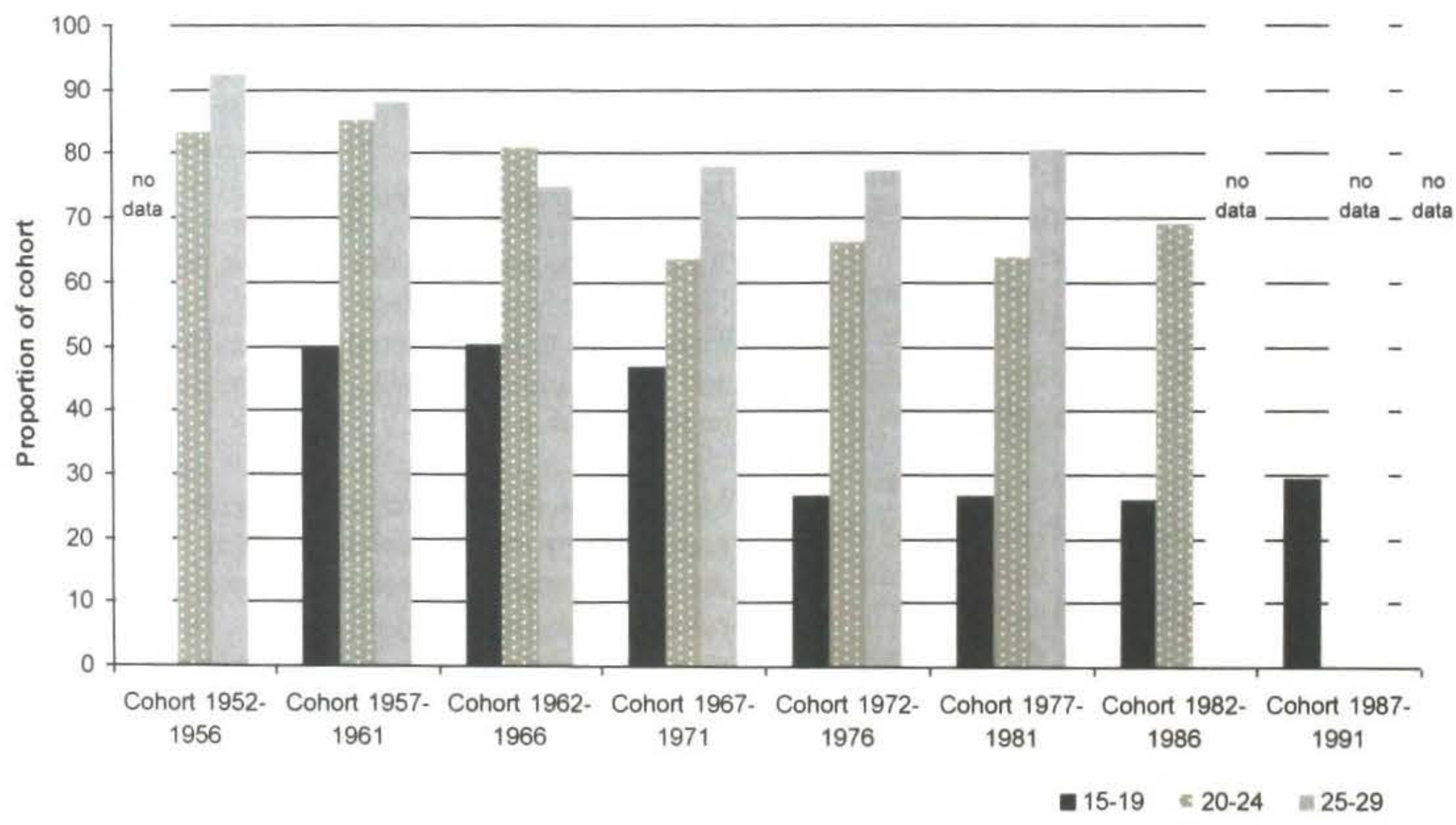

Source: Rea and Callister (2009) 
Figure 3 shows the different trends for young women. While at ages 15-19 there has been a decrease in the proportion in full time employment, at older ages there has been an increase. The different trends for women reflect changes in both education and fertility. Increased participation in education has reduced participation in full time employment, while declines in fertility mean that young women are less likely to be withdrawing from the labour market to look after children.

\section{Figure 3: Proportion of young women in full time employment at ages 15-19, 20-24 and 25-29, selected cohorts}

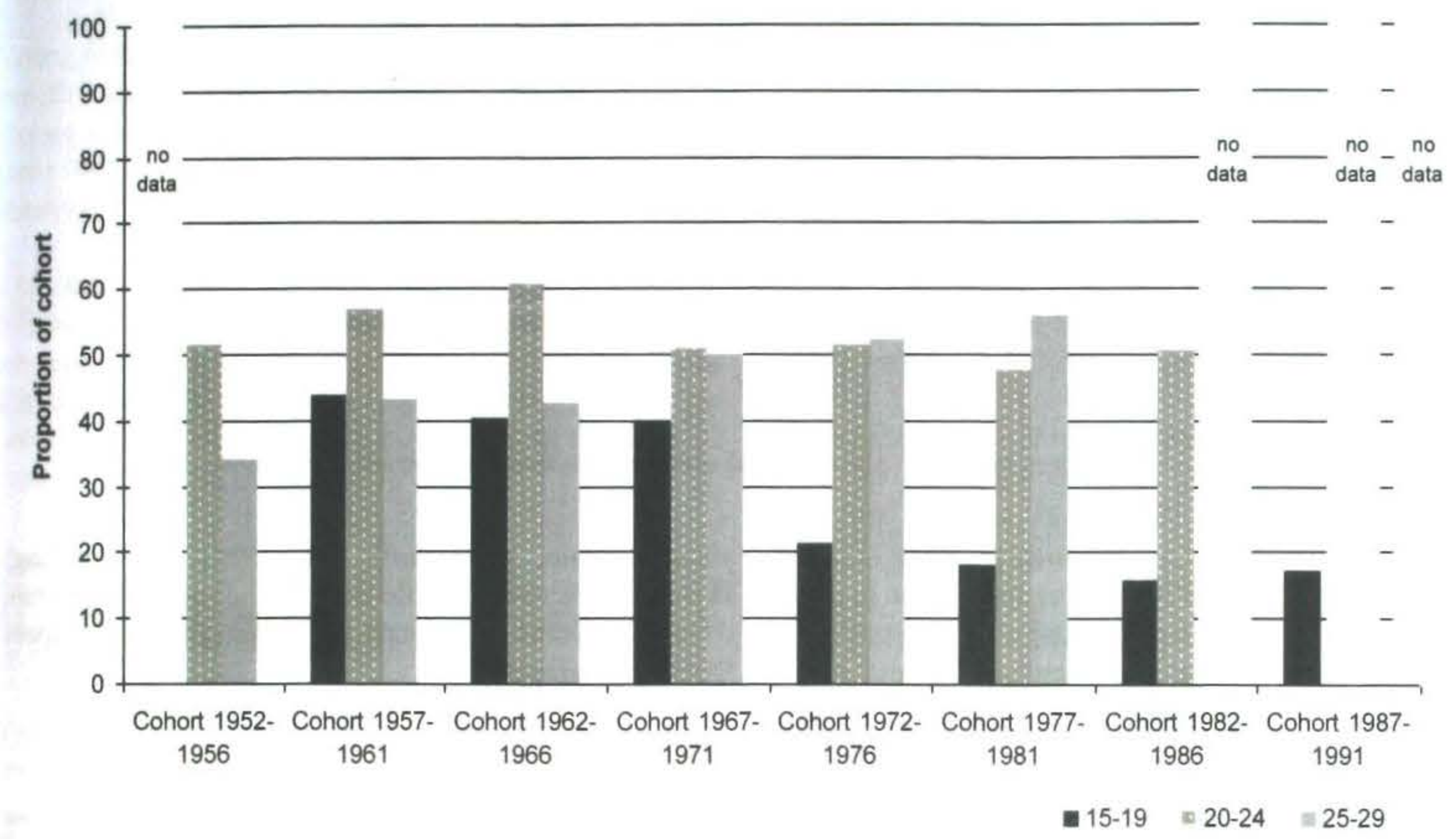

Source: Rea and Callister (2009)

There have also been important changes in the extent of part time work. For both young men and young women there has been an increase amongst recent cohorts of part time work.

Recent census data shows that many young people combining both work and study - particularly at young ages - and much of it part time work. Although there data is not comprehensive, it is reasonable to assume that combining work and study is a trend that has increased over time.

\section{Unemployment}

As young people get older they are less likely to be unemployed. Youth unemployment is highest amongst those aged 15-19, and then declines steadily with age.

Amongst most recent cohorts, young women have a higher prevalence of unemployment than young men. Maori and Pacific young people also have a higher prevalence than young people identifying with other ethnic groups.

Figure 4 shows how the experience of unemployment has differed across cohorts. We report the population prevalence of unemployment (the proportion of the cohort unemployed), rather than the unemployment rate (unemployment as a proportion of those in the labour force). It is also important to note that the Census definition of unemployment is not entirely consistent through time. It became more restrictive in 1991, meaning that the measured level of unemployment experienced by earlier cohorts is over-stated.

Despite this, the extent of unemployment was very low amongst cohorts born in the 1950s. By way of contrast, the cohorts born between 1967 and 1976 experienced very high rates of unemployment. Since that time the incidence of unemployment has declined - although only slightly for those aged 15-19 years. 
Figure 4: Prevalence of youth unemployment amongst New Zealand born cohorts, selected cohorts

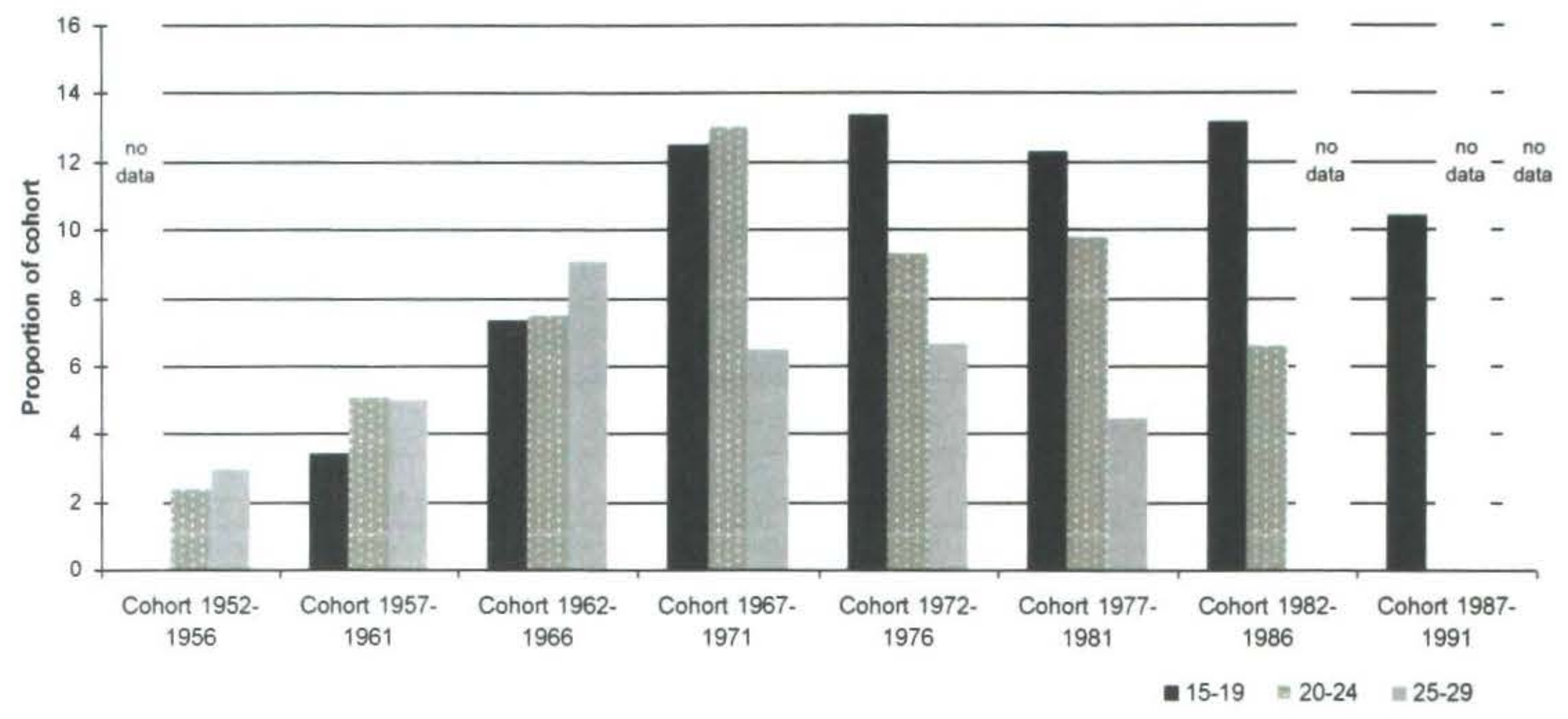

Source: Rea and Callister (2009)

Note: Unemployment as a proportion of population. Also definitional changes in measurement of unemployment in 1991.

The high levels of unemployment amongst those born in the late 1960 s to early 1970 s reflect the labour market conditions that these cohorts faced. These cohorts entered the labour market in the late 1980 s and early 1990 s during a major recession.

The high incidence of unemployment amongst this cohort fell disproportionately on young Maori and Pacific people (Fletcher, 1995; Gobbi and Rea, 2000; Maré, 1995).

Amongst more recent cohorts it is somewhat of a puzzle as to why unemployment has remained high, given the decline in the overall extent of unemployment. We suspect it may partly be because of the increased prevalence of part time and temporary work amongst young people, particularly while they are studying. However it is also possible that the individualised nature of modern youth transitions may mean more time spent looking for employment.

\section{Benefit receipt}

Young people who do not successfully make the transition to employment may end up in receipt of unemployment, sickness, invalids or domestic purposes benefit. A surprising amount of young people rely on benefits at some point over a 12 month period. For example, when the cohort born in the early 1980s were aged $20-24$, around $18 \%$ reported benefit income in the last 12 months. See Figure 5.

Figure 5: Proportion of New Zealand born cohorts reporting benefit use in the last 12 months, selected cohorts

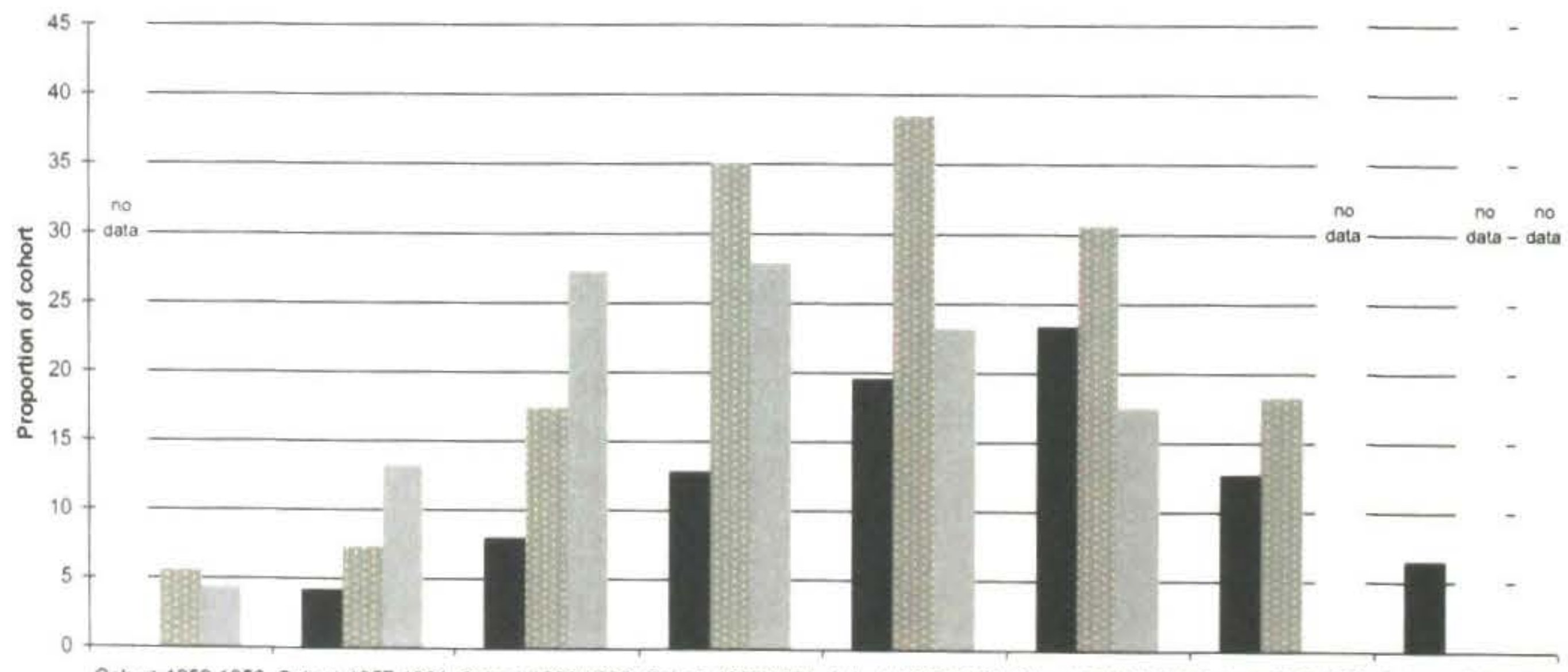

Cohor 1952-1956 Cohort 1957-1961 Cohort 1962-1966 Cohort 1967-1971 Cohort 1972-1976 Cohort 1977-1981 Cohort 1982-1986 Cohort 1987-1991

- $15-19 \quad=20-24 \quad=25-29$

Source: Rea and Callister (2009)

Note: Proportion of the cohort reporting income from a main benefit in the last 12 months 
The prevalence of benefit receipt peaks at 20-24 years of age and then declines. Despite having a higher rate of unemployment, young people 15-19 years of age have a lower prevalence of benefit receipt because of benefit entitlement rules. Up until age 18 years there is only limited entitlement to benefits, as policy generally assumes young people are the financial responsibility of their family.

Young women are more likely than young men to receive benefit income, largely because of the higher rates of receipt of DPB. Maori and Pacific young people are more likely than young people in other ethnic groups to receive benefit income.

The overall trend in benefit use amongst cohorts has followed the rate of unemployment. Benefit use peaked amongst the cohort born in the early 1970s. Amongst this cohort at 20-24 years of age almost $40 \%$ reported being in receipt of a benefit at some point in the prior 12 months.

\section{Real mean personal income}

As young people get older, their real personal incomes grow.

Young men have higher real average personal incomes than young women. Young people identifying as European have higher average incomes than those identifying with other ethnic groups.

In comparing cohort experiences over time, there has, until very recently, been a decline in the real average personal incomes of young men. The cohort born in the early 1950 s had the highest real incomes of any cohort studied.

The cohort trends are different for young women, where there has been a decline in real incomes for those aged 15-19, but an increase in incomes for those aged 25-29.

The cohort trends in incomes reflects a range of factors including participation in education, changes in unemployment, fertility and child rearing, and changes in wage and hours of work.

\section{Religious affiliation}

As young people get older they are less likely to report a religious affiliation. Women are more likely than young men to report religious affiliation. Pacific and Asian are more likely than other ethnicities. The extent of religious affiliation has steadily declined across the cohorts.

\section{Migration within New Zealand}

We measure 'migration' indirectly via the proportion of a cohort indicating they are living in an urban or rural area. The change in the distribution of the cohort living in rural and urban areas is used to infer changes in net migration. The patterns we observe using this method seem to accord with analysis of migration based on changes in usual residence (Statistics New Zealand, 2008).

The proportion of the cohort living in urban areas shows a big increase from aged $15-19$ to $20-24$. There is then a slight decline by age 25-29. We attribute this to migration patterns, particularly because of tertiary education, but also work and partnerships. We suspect that after leaving school, a proportion of young people move from rural to urban areas. It is possible that there is some return at older ages.

Young women are slightly more likely to move than young men. European and to a lesser extent Maori appear more mobile, but this is largely because the other ethnic groups are very highly urbanised to begin with.

The change in the proportion of young people living in rural versus urban areas has increased over time. We interpret this as increased geographically mobility amongst more recent cohorts

\section{International migration}

Like internal migration, we use our data to make inferences about international migration. We do this based on the proportional decline in the size of the New Zealand born cohorts. After accounting for mortality, and also taking into account some level of survey non response, we attribute the decline in the size of each cohort as a net loss through migration.

We find that across all cohorts, by age $25-29$ roughly $20 \%$ of New Zealand born males, and $15 \%$ of New Zealand born females were living overseas.

The extent of the net loss of young people by ages $25-29$ seems to have been increasing. That said, in comparing cohorts, we find that the net loss through migration was highest amongst the cohort born in the early 1970s. Our finding in relation to the higher net migration of the early 1970 s cohorts is somewhat tentative, however. It is possible that this cohort did not leave New Zealand in greater numbers, but instead, a higher than average proportion stopped filling out the Census.

\section{Mortality}

Between the ages of 15 and 24 years around $1 \%$ of young people die. ${ }^{2}$ Young men are about 2.7 times more at risk of mortality than young women. Mortality rates of young Maori are around twice that of non Maori (Child and Youth Mortality Review Committee, 2006).

More recent cohorts are less at risk of mortality. This is primarily due to the decreasing trend in motor vehicle related deaths. However, the second largest contributor to deaths, suicide, has shown a different pattern. Suicide deaths amongst young men peaked amongst the cohort 
born in the late 1960 s early 1970 s cohorts. Suicide deaths amongst cohorts of young women have increased.

\section{Discussion of findings}

The basic question motivating this paper is how labour market transitions have changed for young people over the last 30 years.

Overall, we find that there has been significant change. If we focus on the experience of young people born in the $1980 \mathrm{~s}$, and compare them with those born in the 1950s, we find that the more recent cohorts are:

- $\quad$ living at home longer

- $\quad$ spending more years in education

- moving into full time work at older ages

- more likely to be entering the workforce and working part time work

- $\quad$ probably combining work and study to a greater extent

- amongst young women, more likely to be in the workforce at ages 25-29

- more likely to have an experience of unemployment, and have a higher reliance on benefit receipt

- more geographically mobile, both within New Zealand and overseas

Overall we argue that entry into the labour market has become more complicated than the mid 1970s. Modern youth transitions seem longer, differently structured by gender, more individualised, diverse and less linear. These findings echo what has been observed in other OECD countries (OECD, 2000).

It appears that youth transitions have become longer as young people are remaining in education and entering full time employment at older ages. At the same time young people are living with their parents for longer, and the proportion living with partners or children is decreasing.

There is also considerable change in the structuring of youth transitions by gender.

For young women born in the 1950s, leaving the labour market because of marriage and children was still a dominant pattern. There were explicit barriers to the employment of women in many occupations, and discrimination by employers on the basis of sex was still legal. Amongst more recent cohorts, young women over the age of 20 years are now more likely to be employed. and in a more diverse range of occupations.

For young men born in the early 1950 s, there was also a structured path of full time employment, marriage, and a breadwinner role. Since that time, there has been a decline in male employment, and a weakening of the link between parenting and partnering.
Our analysis only covers ethnicity since 1991, and we are not able to draw any conclusions about whether differences have lessened in the last 30 years. However, our analysis of more recent cohort transitions reveals marked differences between young people identifying with different ethnic groups.

Overall, the decline in structured pathways means more individualised choice and more diversity for young people in the modern labour market.

Our analysis also reveals important findings about how recession impacts upon young people's transition into the labour market.

The cohorts born in the late 1960 s early 1970 s entered a labour market undergoing a severe recession during the late 1980 s and early 1990s. The unemployment rates of these cohorts were unusually high. However across a number of other outcomes, these cohorts also had poor outcomes. Compared to other cohorts, those born in the late 1960 s and early 1970 s had:

- unusually high rates of living with parents

- the highest rates of sole parenthood

- above trend increases in participation in education

- $\quad$ significant reductions in employment

- $\quad$ high rates of benefit receipt

- $\quad$ reduced incomes

- high rates of suicide amongst young men

- and possibly an unusually high rate of net migration.

While there are many influences on outcomes - the different size of cohorts, changing ethnic composition, changing technology, changing gender roles, and different policy settings - the correlation of outcomes with overall levels of unemployment provides plausible evidence of the impact of recession.

Our findings are also supported by a wider literature on the impact of unemployment. Findings from research using the Dunedin and Christchurch longitudinal studies are particularly interesting in this regard, as they represent analysis of cohorts born in the early to mid 1970s. Using the Christchurch study, Maloney (2004) finds evidence that the experience of economic inactivity may have increased the risk of future periods of inactivity. Using the Christchurch study, Fergusson et. al., (2001) find exposure to unemployment slightly elevated the risk of criminal behaviours, court convictions, drug and alcohol abuse and suicidal ideation, but not depression, teenage pregnancy or suicide attempts. Additional evidence of the relationship between unemployment and male suicide is provided by Blakely et al., (2003). Using linked census and mortality data, they find that it was likely that unemployment increased suicide amongst 18 to 24 year old men, even after adjusting for the confounding effects of mental health. 
The transition to employment is a fundamental component of youth development, and where this is inhibited because of unemployment, it is unsurprising that there might be effects in other areas. These include young people remaining in school and education for longer, living at home, going on to benefit, and leaving the country. It is possible that these flow-on effects might also include an increased risk of suicide amongst males, and increased rates of sole parenthood.

\section{Policy implications}

Entry into the labour market is an important aspect of the wider process of youth development. Labour market transitions enable financial independence, but are also important in terms of self esteem and social relationships for young people.

Youth transitions also have wider economic consequences. Education represents an enormous investment in the capital stock of the economy, and the effectiveness with which young people are matched with employers, and able to expand their human capital through on-the-job learning, is critical for future productivity.

The ease with which young people are able to transition into the labour market also has important social consequences. This study points to the relationship between poor transitions and impacts on families, communities and taxpayers.

In what follows we look at the policy implications of our research in three areas. We look at the appropriate policy response to the current economic recession, the nature of the institutional arrangements to support youth transitions more generally, and the groups of young people who deserve more careful attention to ensure successful transitions.

\section{The current recession}

The economy began shrinking in the first quarter of 2008, and the economic forecasts used for Budget 2009 show this trend will continue until the first quarter of 2010. Unemployment is predicted to continue increasing until March 2011 when it is forecast to reach 7.5 percent of the labour force.

If previous recessions are a guide, youth unemployment will rise sharply. This occurs because as labour market entrants, young people make up a large proportion of all people looking for work. For example, the LEED data shows that young people represent around one third of all hires at any point in time. One of the first responses of firms to a downturn is to reduce recruitment, and hence young people are disproportionately impacted by a recession.
A key implication of our study is that the current generation of young people may face prospects that resemble those of the late 1960s early 1970s cohorts. Over the next two years we are likely to see more young people living at home, increased school retention, and many of the other flow-on effects identified above. Maori and Pacific young people are likely to experience these impacts disproportionately.

One area that might be different is international migration, as countries that are potential migration destinations are also experiencing a recession. Reduced outflows of young people, combined with increased numbers of older New Zealanders returning from overseas, may increase youth unemployment.

The fact that the current 'baby blip' cohort is numerically larger than other cohorts will also likely exacerbate problems for this cohort.

Policy to respond to rising to youth unemployment covers many different areas. These include enabling young people to remain at school for longer, enhancing access to tertiary education, subsidising apprenticeships, direct job creation, active labour market and youth development programmes, addressing income issues for young people and their families, and enabling community organisations to provide activities and support for young people.

There is an extensive literature on the relative effectiveness of these different interventions, much of it being canvassed in the current OECD reviews of youth transitions (OECD, 2008).

A wide ranging programme of interventions to address youth unemployment does come at a considerable fiscal cost. However, in considering the costs and benefits of such a programme, it is important to account for the benefits and costs properly. In an environment of high unemployment, the cost to government of keeping a young person in education or an apprenticeship is the opportunity cost of a young person on benefit. Investments in human capital also have longer term benefits.

\section{Institutional design}

In this paper we argue that youth transitions are becoming longer, less structured, and more complicated. These changes might provide some of the explanation for the relative increase in youth unemployment observed amongst the most recent cohorts.

At the same time as youth transitions are becoming more complicated, they are also becoming more important. This is occurring because the amount of time young people spend in education has been increasing. From a purely economic perspective, young people are becoming more valuable because an increasing level of resource is being invested in their education. 
In the medium term, it is important to consider the institutional arrangements that facilitate effective youth transitions. By institutional arrangements we mean the mechanisms that ensure that young people are acquiring labour market relevant skills in education, and efficiently entering into high quality employment when leaving education. These institutional arrangements might include ensuring that young people and their families have timely information about career choices, that there are good links between education providers and employers, and that there are well organised mechanisms (such as apprenticeships) to encourage skill formation.

\section{Addressing disadvantage}

If we look at indicators of youth transitions in New Zealand compared to the OECD, there are some indications that New Zealand has a higher proportion of disadvantaged young people who are not transitioning successfully. New Zealand has a below average number of young people 15-19 years of age in education, and an above average proportion of young people who are not in education or employment (OECD, 2007 and 2009).

Our analysis has only been disaggregated by sex and ethnicity - but a clear finding of our research is that there are systematic differences in the extent to which different groups transition successfully.

Young people identifying with Maori and Pacific ethnicities have, on average, markedly lower rates of participation in all forms of education, are less likely to be employed, are more likely to be unemployed, are more likely to be receiving benefits, and are more likely to be parents. Young Maori also have a significantly higher rate of mortality than non-Maori.

If we look at transitions by gender, young unskilled men, and the group of mostly young women who become sole parents at any early age stand out as groups for whom transitions are difficult.

Addressing the underlying causes of this disadvantage is important from both an economic as well as social equity perspective

\section{Conclusion}

This paper has drawn on our wider study of cohort differences in youth transitions. The focus of this paper has been the changing nature of the transition into the labour market.

In looking at how the transitions into the labour market have changed, there are two main conclusions.

First, more recent cohorts are spending longer in education, are entering full time employment later, and are probably combining education and part-time work to a greater degree. More generally, labour market transitions seem more individualised and also more diverse.

Second, the overall state of the economy has wide ranging effects on youth transitions. The cohorts born in the late 1960 and early 1970s entered a labour market in recession, and experienced outcomes that were somewhat different compared to both earlier and later cohorts.

There are a variety of important policy implications from considering youth transitions in an historical context. These include responding to the current recession, ensuring that labour market institutions support youth transitions, and also identifying and addressing the reasons why some young people are less likely to transition successfully.

There are many questions in this area that might usefully be a focus of further research. These include the reasons for the relative rise in youth unemployment compared to other age groups, and the reasons for the differences in transition outcomes between ethnic groups. More generally, increasing the evaluation evidence about the effectiveness of particular initiatives within a New Zealand context is also critical.

\section{Acknowledgements:}

The findings, opinions and conclusions expressed in this paper are strictly those of the authors. We would especially like to thank Trish Morant from Statistics New Zealand for assistance with the data. A wide range of people have also given us valuable feedback on the wider research study upon which this article is based. These include Jonathan Boston, Marny Dickson, Rebecca Martin, Amy Russell, Doug Gorman, Len Cook, Andy Rigg, and Michelle Basham.

\section{Notes}

1. These statistics are derived from administrative enrolment data recorded in Education Statistics of New Zealand.

2. This section uses data from the Statistics New Zealand cohort life tables

\section{References}

Blakely, T., Collings, S. and Atkinson, J. (2003). Unemployment and suicide. Evidence for a causal association? Journal Epidemiology and Community Health, 57, 8, pp. 594-600.

Child and Youth Mortality Review Committee, Te Rōpū Arotake Auau Mate o te Hunga Tamariki, Taiohi (2008). Fourth Report to the Minister of Health: Reporting Mortality 20022005. 
Deaton, A. (1985). Panel data from time series of crosssections. Journal of Econometrics, 30, 1-2, pp. $109-126$.

Fergusson, D., Horwood, J. and Woodward, L. (2001). Unemployment and psychosocial adjustment in young adults: causation or selection? Social Science \& Medicine, 53, 3, pp. 305-320.

Fletcher, M. (1995). Pacific Islands Peoples in the Labour Market. Labour Market Bulletin, 1, pp. 124-136.

Gobbi, M. and Rea, D. (2002). The unemployment spells of registered jobseekers. Labour Market Bulletin, 2002, 2, pp. 31-56.

Maloney, T. (2004). Isolating the Scarring Effects Associated with the Economic Inactivity of Youth in New Zealand: Evidence from the Christchurch Health and Development Study, Report to the Labour Market Policy Group, Department of Labour

Maré, D. Examining Labour Market Outcomes for Mäori. Labour Market Bulletin, 1, pp. 116 - 123.

Mazengarb, O. C. (1954). Report of the Special Committee on Moral Delinquency in Children and Adolescents, Wellington: Government Print.

OECD. (2000). From Initial Education to Working Life: Making Transitions Work, Paris: OECD.

OECD. (2007). Education at a Glance 2007, Paris: OECD.

OECD. (2008). Jobs for Youth: New Zealand, Paris: OECD.

OECD. (2009). Society at a Glance 2009, Paris: OECD.

Rea, D. and Callister, P. (2009). The changing nature of young people's transitions in New Zealand, Institute of Policy Studies Working Paper.

Settersten, R., Furstenberg, F. and Rumbaut, R. (eds) (2005). On the Frontier of Adulthood: Theory, Research, and Public Policy, Chicago: The University of Chicago Press.

Ryan, P. (2001). The School-to-Work Transition: A Cross-National Perspective. Journal of Economic Literature, 39, 1, pp. 34-92.

Schlegel, A. and Barry, H. (1991). Adolescence: An Anthropological Inquiry. New York: Free Press.
Statistics New Zealand. (2005). Understanding and working with ethnicity data: A technical paper, Statistics New Zealand.

Statistics New Zealand. (2008). Internal migration, Wellington: Statistics New Zealand.

\section{Authors}

David Rea

Visiting Research Fellow

Institute of Policy Studies

Victoria University of Wellington

P.O. Box 600

Wellington 6140

David.Rea@vuw.ac.nz

\section{Paul Callister}

Deputy Director

Institute of Policy Studies

Victoria University of Wellington

P.O. Box 600

Wellington 6140

Paul.Callister@vuw.ac.nz 